\title{
Factors Affecting Color Reproducibility of Resin-veneered Prostheses
}

\author{
Rena Ikoma ${ }^{1}$, Naomi Tanoue ${ }^{2}$, Taku Fujiwara ${ }^{3}$, Takashi Sawase ${ }^{4}$ \\ ${ }^{l}$ Department of Applied Prosthodontics, Nagasaki University Graduate School of Biomedical Sciences, Japan \\ ${ }^{2}$ Division of Specialized Dentistry, Nagasaki University Hospital, Japan \\ ${ }^{3}$ Department of Pediatric Dentistry, Nagasaki University Graduate School of Biomedical Sciences, Japan \\ ${ }^{4}$ Department of Applied Prosthodontics, Nagasaki University Graduate School of Biomedical Sciences, Japan
}

\begin{abstract}
The aim of this study was to evaluate the color difference between the facing of resin-veneered prostheses after fabrication and the original shade guide tab specified, as well as to investigate the factors affecting reproducibility. A total of 187 resin-veneered prostheses were fabricated and the color of the veneer facing was compared with the Vita Lumin Classical Shade Guide tab specified. Information regarding the shade guide tab, tooth type, position, dental laboratory, and resin material was recorded. The veneer facing of the completed prosthesis was colorimetrically measured in three regions (incisal, body, and cervical) by a spectrophotometer, and the color of the target shade guide tab was measured in the same way. The color difference $\left(\Delta E^{*}\right)$ between the veneer facing and the shade guide tab was calculated and statistically analyzed using a mixed effect model at 5\% significance level. The region $(p<0.0001)$, shade group $(p=0.0006)$, and tooth type $(p=0.0066)$ significantly affected the $\Delta E^{*}$ values. When regions of the tooth were compared, the biggest $\Delta E^{*}$ value was recorded in the incisal region. Our results suggest that the region of the veneer facing is the most influential factor on color reproducibility of composite resin-veneered prostheses.
\end{abstract}

Keywords: color, reproducibility, resin-veneered prosthesis, shade guide

\section{Introduction}

When providing a patient with an aesthetic prosthesis, the color suitability contributes greatly to patient satisfaction. Generally, the suitability of the color is influenced by two factors: appropriate color selection and correct reproduction of the color selected. If one or both of these two processes are not adequately accomplished, the patient may not be satisfied. The use of a dental spectrophotometer helps to overcome problems with color selection [1-10]. However, many other complicated factors play a part in correct reproduction of the selected color.

In the case of indirect aesthetic prostheses, color reproduction is mainly entrusted to dental technicians. In prostheses in which metal is used as the background material, such as metal ceramic and resin-veneered restorations, it is even more important that the dental technician is able to reproduce the correct and appropriate color, because such prostheses are not affected by the color of the cement selected and used by dentists.

During the process of fabricating prostheses, there are many factors affecting color reproducibility. For example, the thickness of the tooth-colored material used for veneering or facing is one of the most important factors for reproducibility [11, 12], as is the performance of the material itself [13]. Colorimetric characteristics, including lightness, are reported to affect the replication of color shades. For example, Yilmaz et al. reported that the replication of high-value shades was observed to be reliable [9], and Lagouvardos et al. indicated that some shades produced a more reliable and valid match than others regardless of the brightness [14]. Other factors such as the region of the crown [15-17] and the type of shade guide used to select the color in the dental office and in the dental laboratory $[2,13,14,18-20]$ have also been reported to be related.

In particular, the color matching ability of the dental technician has a significant influence on reproducibility. $[20,21]$ This relates not only to the artistic skill of the dental technician, but also to the dental laboratory in which the technician works [15], including its equipment, the materials available, the environment, and working conditions and wages. Generally, dental technicians' shade-matching abilities improve under lightcorrective devices compared with conventional laboratory lighting conditions [22, 23]. For adequate shade matching, relevant uncovered costs are needed for dental laboratories [24].

An aesthetic prosthesis is commonly made to match neighboring teeth as well as the selected shade guide tab, because natural teeth often have individual colorimetric characteristics such as stripes and cracks that the shade guide tab does not include. Colorimetric evaluation of a prosthesis with complicated color design is therefore extremely difficult. Accordingly, in this study, we selected and assessed prostheses fabricated to match a shade guide color to more easily clarify the factors that contribute to color reproducibility. The null hypothesis tested was that the factors examined in this study of shade guide tab, tooth type, position (maxilla or mandible), dental laboratory, and resin material had no effect on color reproducibility. 


\section{Materials and methods}

Between 2010 and 2012, 216 resin-veneered prostheses for the central incisor, lateral incisor, canine, and first premolar were sent for fabrication to five dental laboratories in Nagasaki Prefecture, Japan by the dentists of Nagasaki University Hospital. The most suitable shade had been previously selected by dentists using the Vitapan Classical shade guide (VITA Zahnfabrik, Bad Säckingen, Germany) and was specified in the documentation. We asked the laboratories to add details of the material used for veneering to the documentation.

All the prostheses were fabricated and delivered to the hospital within approximately 10 days after ordering. Prostheses that included specialized colorimetric instructions such as stripes and cracks were excluded from the study. Also excluded were prostheses for which we could not identify the resin material type. A total of 187 resin-veneered prostheses were assessed in this study.

For color measurement, a dental spectrophotometer system (Crystaleye, Olympus, Tokyo, Japan) was used. To demonstrate the repeatability of the color measurement, the 16 shade tabs of the Vitapan Classical shade guide were used. The shade guide tabs were removed from the holder and the metal handles were detached. Each shade tab was fixed in the position of the right central incisor of the maxilla of the model included in the system. The model was securely placed in a black box (Inspection Kit, Olympus), and the colorimetric image analyzing software (Crystaleye Application Master Ver. 1.4, Olympus) was focused on the central region of the tab surface. A standardized region (a square approximately $2.0 \mathrm{~mm}$ in width and $10 \times 10$ pixels in height; one pixel $=0.2 \mathrm{~mm}$ ) and its position were set automatically, and the $\mathrm{L}^{*}, \mathrm{a}^{*}$, and $\mathrm{b}^{*}$ values were recorded using the Commission Internationale de l'Eclairage (CIE) Lab color system. Measurements were taken five times for each tab. Repeatability was analyzed using the intraclass correlation coefficient (ICC). For each $\mathrm{L}^{*}, \mathrm{a}^{*}$, and $\mathrm{b}^{*}$ value, one-way analysis of variance was performed, and the ICC was calculated. We aimed to achieve almost perfect reliability $(\mathrm{ICC}=0.81-1.00)$.

The fabricated prostheses were fixed to the model in a precise position using transparent adhesive tape on the lingual/palatal side. The model was securely placed in the black box (Inspection Kit) and the color was measured in the same way as in the repeatability measurement, but in three regions (incisal, body, and cervical) of the veneer facing. Each standardized region (as in the assessment of the performance of the spectrophotometer) and its position were set automatically. The color of each region was measured five times, and the mean value was calculated as data peculiar to a prosthesis.

The target shade guide tab without metal handle was fixed in the position of the right central incisor of the maxillary model, and was colorimetrically measured in the three regions in the same way as for the prosthesis. The color difference $\left(\Delta \mathrm{E}^{*}\right)$ between the prosthesis and the target shade tab in the same region was calculated using the following formula:

$$
\Delta \mathrm{E}^{*}=\left(\left[\Delta \mathrm{L}^{*}\right]^{2}+\left[\Delta \mathrm{a}^{*}\right]^{2}+\left[\Delta \mathrm{b}^{*}\right]^{2}\right)^{1 / 2}
$$

The assessed factors were (1) region (incisal / body / cervical); (2) position (maxilla / mandible); (3) tooth type (central incisor / lateral incisor / canine / first premolar); (4) shade group according to shade tab number (the [1,2] group / the [3] group / the [3.5, 4] group); (5) dental laboratory (A / B / others); (6) resin material (Solidex / Signum Sirius / Prime Art / others). Information about the three veneering composites is shown in Table 1.

Table 1. Details of the veneering composites used.

\begin{tabular}{|l|l|l|l|l|}
\hline Product & Filler composition & Filler loading & Resin composition & Manufacturer \\
\hline Solidex & $\begin{array}{l}\text { Splintered glass (average } 3 \mu \mathrm{m}), \\
\text { colloidal silica, prepolymerized silica } \\
\text { composite }\end{array}$ & $\begin{array}{l}78 \mathrm{wt} \% \text { of total filler } \\
53 \mathrm{wt} \% \text { of inorganic } \\
\text { filler }\end{array}$ & UDMA, others & $\begin{array}{l}\text { Shofu Inc., } \\
\text { Kyoto, Japan }\end{array}$ \\
\hline $\begin{array}{l}\text { Signum } \\
\text { Sirius }\end{array}$ & $\begin{array}{l}\text { Silica, prepolymerized silica } \\
\text { composite }\end{array}$ & $74 \mathrm{wt} \%$ of total filler & $\begin{array}{l}\text { Dodecanediol dimethacrylate, } \\
\text { polyfunctional methacrylate }\end{array}$ & $\begin{array}{l}\text { Heraeus Kulzer } \\
\text { GmbH, Hanau, } \\
\text { Germany }\end{array}$ \\
\hline $\begin{array}{l}\text { Metacolor } \\
\text { Prime Art }\end{array}$ & $\begin{array}{l}\text { Prepolymerized silica composite, } \\
\text { hydrophobic colloidal silica, barium } \\
\text { silica glass }\end{array}$ & $73 \mathrm{wt} \%$ of total filler & $\begin{array}{l}\text { UDMA, TEGDMA, aromatic } \\
\text { amine, others }\end{array}$ & $\begin{array}{l}\text { Sun Medical Co., } \\
\text { Moriyama, Japan. }\end{array}$ \\
\hline
\end{tabular}

UDMA: Urethane dimethacrylate, TEGDMA: Triethylene glycol dimethacrylate

The factors that statistically affected the $\Delta \mathrm{E}^{*}$ values were evaluated using a mixed effect model taking the hierarchical structure into consideration $(\alpha=0.05)$. The mean and standard deviations for the $\Delta \mathrm{E}^{*}, \Delta \mathrm{L}^{*}$, $\Delta \mathrm{a}^{*}$, and $\Delta \mathrm{b}^{*}$ values were calculated for each set of specimens and compared by Tukey tests $(\alpha=0.05)$ to determine statistically effective factors. All analyses were carried out using statistical analyzing software (JMP Pro 11.2.0, SAS Institute Inc., Tokyo, Japan).

\section{Results}

The ICC values of $\mathrm{L}^{*}, \mathrm{a}^{*}$, and $\mathrm{b}^{*}$ were $0.997,0.989,0.997$, respectively. These results indicated that the repeatability of the spectrophotometer used was reliable enough for color measurement. 
Among the six evaluated factors, the distributions of the factors of resin material and dental laboratory were quite similar. Therefore, the factor for resin material was removed to take multicollinearity into account. A mixed effect model of the remaining five fixed effects and one random effect (identification code) was performed. The statistical results for the fixed effects are shown in Table 2.

Table 2. Statistical analysis of fixed effects following the mixed effect model

\begin{tabular}{|c|r|r|r|r|}
\hline Factor & Parameters & Degree of freedom & F value & $p$ value \\
\hline Region & 2 & 2 & 53.4255 & $<0.0001$ \\
\hline Position & 1 & 1 & 0.0003 & 0.9855 \\
\hline Tooth type & 3 & 3 & 4.2178 & 0.0066 \\
\hline Shade group & 2 & 2 & 7.7364 & 0.0006 \\
\hline Dental laboratory & 2 & 2 & 2.5239 & 0.0830 \\
\hline
\end{tabular}
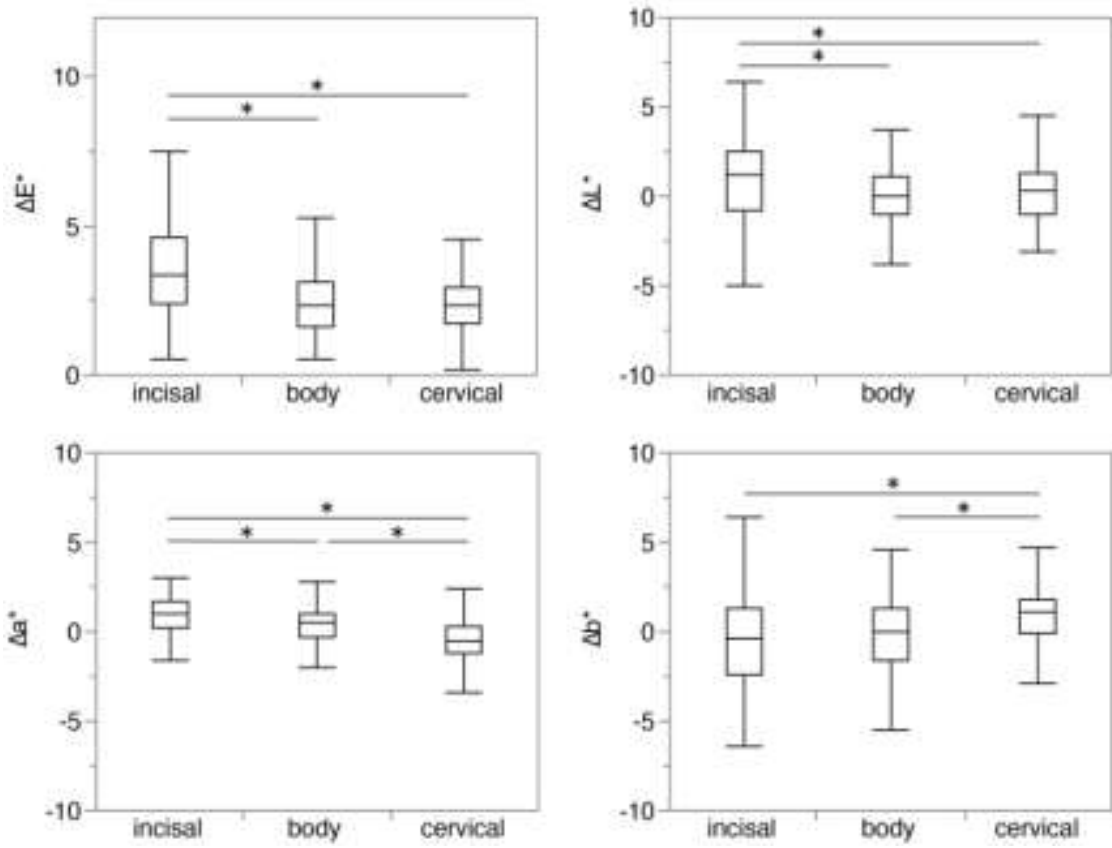

Fig. 1 Results of the $\Delta \mathrm{E}^{*}, \Delta \mathrm{L}^{*}, \Delta \mathrm{a}^{*}$, and $\Delta \mathrm{b}^{*}$ values compared according to the region of the tooth (incisal / body / cervical). ${ }^{*} p<0.05$.
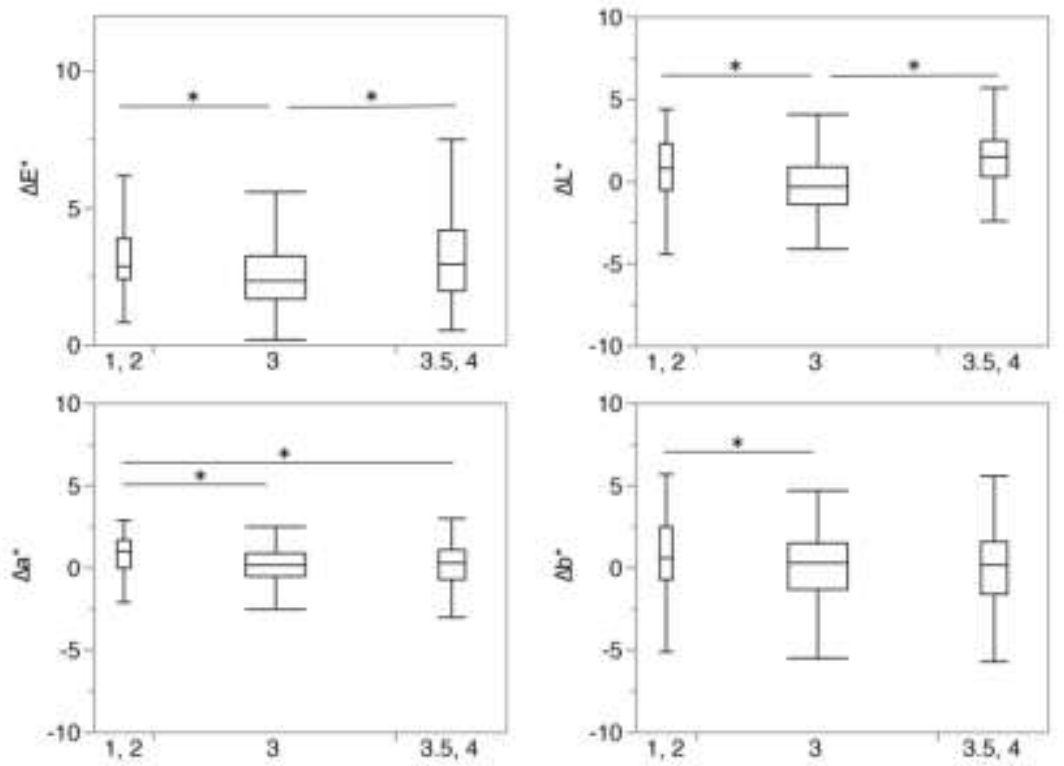

Fig. 2 Results of the $\Delta \mathrm{E}^{*}, \Delta \mathrm{L}^{*}, \Delta \mathrm{a}^{*}$, and $\Delta \mathrm{b}^{*}$ values compared according to shade tab number $(1,2 / 3 / 3.5,4) . * p<0.05$. 
The results of the $\Delta \mathrm{E}^{*}, \Delta \mathrm{L}^{*}, \Delta \mathrm{a}^{*}$, and $\Delta \mathrm{b}^{*}$ values for the three most effective factors and the statistical post-hoc comparison are shown in Figs 1-3. The factor of region, as seen in Fig. 1, was the most influential, and the $\Delta \mathrm{E}^{*}$ value of the incisal region was the highest. Specifically, the $\Delta \mathrm{L}^{*}$ and $\Delta \mathrm{a}^{*}$ values of the incisal region were statistically higher in a positive direction. Regarding the factor of shade group according to shade tab number as seen in Fig. 2, the $\Delta \mathrm{E}^{*}$ value of the [3] group was the lowest statistically. The $\Delta \mathrm{L}^{*}$ values of the other two shade groups were also greater in a positive direction. For the factor of tooth type as shown in Fig. 3, the first premolar exhibited the highest $\Delta \mathrm{E}^{*}$ value. This could be because the $\Delta \mathrm{L}^{*}$ value of the premolar was the greatest in a negative direction.
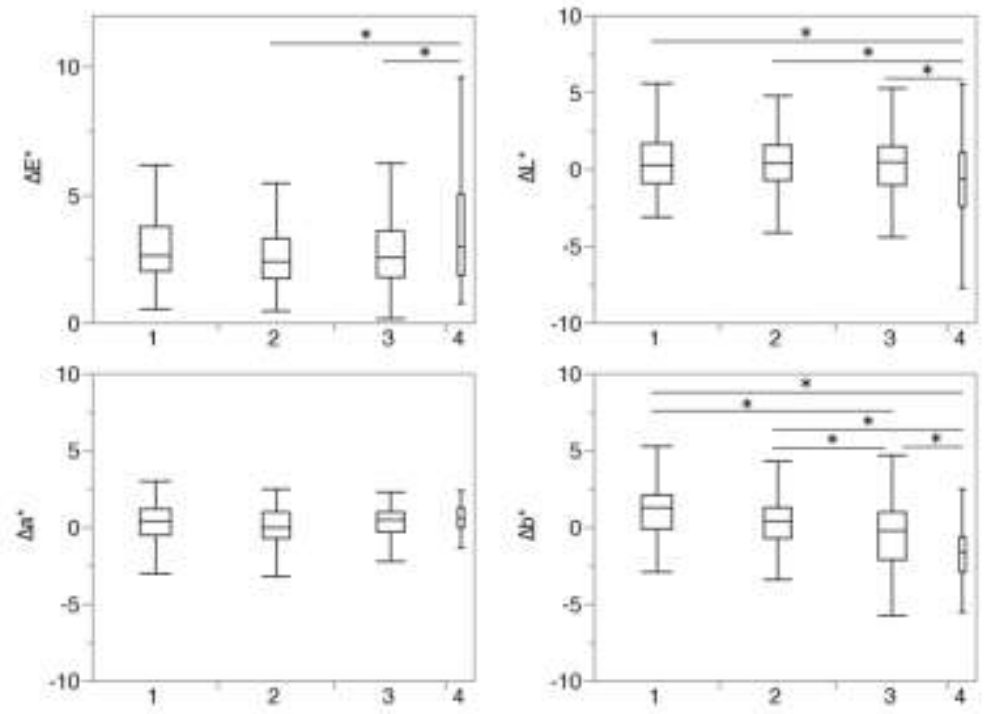

Fig. 3 Results of the $\Delta \mathrm{E}^{*}, \Delta \mathrm{L}^{*}, \Delta \mathrm{a}^{*}$, and $\Delta \mathrm{b}^{*}$ values compared according to tooth type; 1: central incisor, 2: lateral incisor, 3: canine, 4: first premolar. ${ }^{*} p<0.05$.

\section{Discussion}

In this study, six factors related to the reproduction of shades were assessed, and three factors were shown to be influential. The factor of the region of the prosthesis veneer facing was shown to be the most significant. Many researchers have evaluated the reproducibility of prostheses made from porcelain and/or zirconia, and reported that dental laboratories were better at matching shades in the incisal region of the crown than those in the cervical and body regions [15-17]. In this study, however, the incisal region exhibited the greatest $\Delta \mathrm{E}^{*}$ value. This was because the $\Delta \mathrm{L}^{*}$ and $\Delta \mathrm{a}^{*}$ values were high in a positive direction. This means that the incisal region was made to be redder and lighter. The incisal region should be particularly carefully fabricated in aesthetic restorations, because it is more visible than other regions of the tooth. The reason for insufficient color reproducibility in this region could not be isolated within the limitations of this study, but a possible reason is that our study used only resin-veneered crowns but not porcelain or zirconia. Accurate shade matching and correction require significant costs [24]. It may be difficult to achieve minute color reproduction in a composite resin prosthesis within a limited budget.

The shade group according to shade tab number also affected color reproduction, and the [3] group recorded the lowest color difference. Shade tab number is one consideration related to lightness. Color matching using the Vita Classical Guide is reported to achieve good matches for natural unstained teeth [20] and highvalue shades (A1 and B1) [25]. However, according to Lagouvardos et al., reproducibility is mostly unrelated to shade tab number [14]. In this study, the [1,2] group recorded relatively higher $\Delta \mathrm{L}^{*}, \Delta \mathrm{a}^{*}$, and $\Delta \mathrm{b}^{*}$ values than the [3] group. Finch et al. reported that most metal ceramic restorations were lighter than the corresponding shade tab [12], and this is consistent with our results.

The influence of tooth type was also significant. Lasserre et al. reported that the reproducibility and reliability for canines were generally higher than those for central incisors [8]. However, we found no statistical difference between the central incisor and canine except for the $\Delta \mathrm{b}^{*}$ value; and the color of the prosthesis became lighter and yellower toward the anterior. Taking the region and tooth type results into consideration (Figs. 1 and 3), the anterior teeth, especially the incisors, should be fabricated in a lighter shade to achieve optimal aesthetics.

In this study, the distributions of the factors of resin material and dental laboratory were so similar that the resin material factor was removed for accurate statistical analysis. As a result, the factor of dental laboratory was shown to be ineffectual, i.e., both resin material and dental laboratory factors were unimportant. Sufficient 
reproducibility is often achieved as a result of the skill of the dental technician and an appropriate environment for fabrication, and the ability to reproduce the color of the target shade is likely to differ among laboratories $[15,22]$. The lack of significance in this study might be a result of having $\Delta \mathrm{E}^{*}$ values lower than 3.7 , because values below 3.7 were considered to be clinically acceptable [26]. In other words, the quality of the dental laboratory assessed was high enough to produce color-matched restorations. It should also be added that the composition of the resin materials used did not vary substantially (Table 1). In general, the amount of change within the color parameter is thought to be dependent on the material [1].

The main limitation of the present study is that only six factors were evaluated. Of course, it is obvious that other factors also contributed to the results. For example, it seems probable that an adequate thickness of resin material contributes to sufficient color reproducibility. Thick resin material requires a significant degree of preparation on the labial (buccal) side to create space for the veneer. Nevertheless, this factor was excluded from the analysis because measuring the degree of preparation or the thickness of the resin material was difficult to incorporate into the protocol of this study. Accordingly, future research could evaluate additional influential factors.

\section{Conclusion}

Within the limitations of this study, it was concluded that the most influential factor on color reproducibility of composite resin-veneered prostheses was the region of the veneer facing. It should be noted that the incisal region of the anterior teeth is likely to be lighter than the target shade tab.

\section{References}

[1] Wee AG, Monaghan P, Johnston WM. Variation in color between intended matched shade and fabricated shade of dental porcelain. J Prosthet Dent 2002;87:657-66.

[2] Klemetti E MA, Haag P, Kononen M. Shade selection performed by novice dental professionals and colorimeter. J Oral Rehabil 2006;33:31-5

[3] Derdilopoulou FV, Zantner C, Neumann K, et al. Evaluation of visual and spectrophotometric shade analyses: a clinical comparison of 3758 teeth. Int J Prosthodont 2007;20:414-6.

[4] Li Q, Wang YN. Comparison of shade matching by visual observation and an intraoral dental colorimeter. J Oral Rehabil 2007;34:848-54.

[5] Judeh A, Al-Wahadni A. A comparison between conventional visual and spectrophotometric methods for shade selection. Quintessence Int 2009;40:e69-79.

[6] Kanawati A, Richards MW. Repeatability of a dental shade-matching instrument when compared to traditional visual methods of shade evaluation. Gen Dent 2009;57:323-7.

[7] Yoshida A, Miller L, Da Silva JD, et al. Spectrophotometric analysis of tooth color reproduction on anterior all-ceramic crowns: Part 2: color reproduction and its transfer from in vitro to in vivo. J Esthet Restor Dent 2010;22:53-63.

[8] Lasserre JF, Pop-Ciutrila IS, Colosi HA. A comparison between a new visual method of colour matching by intraoral camera and conventional visual and spectrometric methods. J Dent 2011;39 Suppl 3:e29-36.

[9] Yilmaz B, Karaagaclioglu L. In vitro evaluation of color replication of metal ceramic specimens using visual and instrumental color determinations. J Prosthet Dent 2011;105:21-7.

[10] Ozat PB, Tuncel I, Eroglu E. Repeatability and reliability of human eye in visual shade selection. J Oral Rehabil 2013;40:958-64

[11] Koishi Y, Tanoue N, Matsumura H, et al. Colour reproducibility of a photo-activated prosthetic composite with different thicknesses. J Oral Rehabil 2001;28:799-804.

[12] Finch K, Jarad FD, Adeyemi AA, et al. An audit of shade reproduction of fixed metal ceramic prostheses. Eur J Prosthodont Restor Dent 2011;19:94-8.

[13] Wee AG MP, Johnston WM. Variation in color between intended matched shade and fabricated shade of dental porcelain. J Prosthet Dent 2002;87:657-66.

[14] Lagouvardos PE, Diamanti H, Polyzois G. Effect of individual shades on reliability and validity of observers in colour matching Eur J Prosthodont Restor Dent 2004;12:51-6.

[15] Douglas RD, Brewer JD. Variability of porcelain color reproduction by commercial laboratories. J Prosthet Dent 2003;90:339-46.

[16] Ishikawa-Nagai S, Ishibashi K, Tsuruta O, et al. Reproducibility of tooth color gradation using a computer color-matching technique applied to ceramic restorations. J Prosthet Dent 2005;93:129-37.

[17] Abualsaud H, Zandparsa R, Hirayama H, et al. Color management of the cervical region using different framework materials. J Esthet Restor Dent 2011;23:371-8.

[18] King KA, deRijk WG. Variations of L*a*b* values among Vitapan Classical Shade Guides. J Prosthodont 2007;16:352-6.

[19] Al-Hamdan EM HI, Tashkandi E. Evaluation of Color Duplication in Metal-Ceramic Complexes Using Visual and Instrumental Shade-Matching Systems. Int J Prosthodont 2010;23:149-51.

[20] Alomari M, Chadwick RG. Factors influencing the shade matching performance of dentists and dental technicians when using two different shade guides. Br Dent J 2011;211:E23.

[21] Çapa N, Malkondu Oz, Kazazoğlu E, et al. Evaluating factors that affect the shade-matching ability of dentists, dental staff members and laypeople. J Am Dent Assoc 2010;141:71-6.

[22] Jasinevicius TR, Curd FM, Schilling L, et al. Shade-matching abilities of dental laboratory technicians using a commercial light source. J Prosthodont 2009;18:60-3.

[23] Corcodel N HS, Rammelsberg P, Hassel AJ. Metameric effect between natural teeth and the shade tabs of a shade guide. Eur J Oral Sci 2010;118:311-6.

[24] Corcodel N, Zenthöfer A, Setz J, et al. Estimating costs for shade matching and shade corrections of fixed partial dentures for dental technicians in Germany: A pilot investigation. Acta Odontol Scand 2011;69:319-20.

[25] Yilmaz B, Yuzugullu B, Cinar D, et al. Effects of shade tab arrangement on the repeatability and accuracy of shade selection. J Prosthet Dent 2011;105:383-6.

[26] Johnston WM, Kao EC. Assessment of appearance match by visual observation and clinical colorimetry. J Dent Res 1989;68:81922. 